\title{
HETEROCRONIA NA ARQUITETURA: O PROJETO COMO VIABILIZADOR DO PATRIMÔNIO ARQUITETÔNICO E DE SEU ENTORNO
}

\author{
Heterochrony at Architecture: \\ The project as an enabler of the architectural heritage and of its \\ surroundings
}

\section{Simone Back Prochnow}

Mestre em Arquitetura e Urbanismo pela FAU-UNIRITTER em convênio com a FAU-MACKENZIE. arq.sbp@gmail.com

\section{Resumo}

A arquitetura nos permite experimentar lugares que atravessam a dimensão do tempo de nossa existência. Por ser testemunho dos acontecimentos, modos de viver e de pensar de cada época, a arquitetura é naturalmente composta de partes construídas em diferentes momentos. Sua composição admite paradoxos: às vezes, deve e consegue permanecer estática e, às vezes, precisa admitir as mudanças que ocorrem na sociedade, acompanhando sua evolução. A preservação e a permanência dessa arquitetura têm hoje inúmeras maneiras criativas de contemplar o reuso do patrimônio arquitetônico. A heterocronia, ou seja, as alterações, são necessárias para a permanência da arquitetura, adequada às demandas de nosso tempo e ao seu entorno, num processo contínuo de vida de um conjunto maior - a cidade.

Palavras-chave: Memória. Patrimônio histórico. Projeto arquitetônico. Heterocronia.

\begin{abstract}
Architecture allows us to experience places that go beyond our own existence. As a testimony of our development and our way of inhabiting them, cities are naturally composed by different parts, built in different times. That is the paradox that makes it so interesting: cities have to stay as well as continuously advance and change. Permanence is becoming harder in this context of hurry and lack of values that our society lives in and therefore our memory concepts nowadays are somehow vulnerable. But this permanency still has several ways to happen - and to turn architectural heritage as well as architecture obsolete industrial pieces into creative and alive places is the real challenge. This heterochrony, that means, these alterations, are necessary for our heritage survival, adapted to our current demands and to its sorroundings, as part of a bigger and continuous live process - the city.
\end{abstract}

Keywords: Memory. Architectural heritage. Architectural design. Heterochrony.

\section{Sumário}

1. Introdução; 2. Algo de teoria e seus pensadores; 3. Novas diretrizes; 4. Algumas considerações; 5. Notas; Referências 


\section{INTRODUÇÃO}

É facilmente perceptível o aumento da velocidade nas mudanças em nossas vidas e no mundo atual. Conceitos já considerados triviais como obsolescência programada, efemeridade, volatilidade e vida líquida fazem parte de um repertório preocupante se pensarmos em arquitetura e especialmente em patrimônio. A grande revolução da informação que vivenciamos está alterando a relação espaço/tempo, a maneira de nos relacionarmos uns com os outros e com nossas próprias decisões e memórias. Há uma proliferação de pontos de vista presentes a cada discussão, a cada conversa. Como solucionar tantos impasses em nossas cidades com relação às novas demandas? Como abrir espaço para a evolução sem perder a conexão com o que existiu, com nossos valores?

Pessoas muito bem informadas e conectadas com o mundo trabalham em profissões que há poucos anos não existiam; massas de jovens defensores de novas práticas mais saudáveis de vida compartilham ideias e organizam grandes movimentos num estalar de dedos; um grande número de pessoas maduras se mantém ativa por mais tempo, mais longeva e consumidora de novas experiências e de novos lugares. Todos estes cidadãos, muitos de diferentes origens, conformam as cidades e se relacionam, cada qual, com sua bagagem de vivência e de interpretação dos fatos e dos lugares de um modo diferente e único.

Como esta intrigante maneira de viver que hoje se apresenta, se posiciona com relação à arquitetura, por exemplo? Que lugar diríamos que o patrimônio histórico arquitetônico ocupa no nosso dia-a-dia perante esta pós-moderna maneira de viver? Podem as edificações históricas ter sua permanência viabilizada economicamente, sem se tornar exclusivamente museus? Que vantagens podem existir em se reutilizar edifícios considerados obsoletos? Como compatibilizar novos projetos com as edificações históricas existentes? Com projetos que materializem respostas aos anseios e às necessidades do mundo atual.

Projetos arquitetônicos com certa heterocronia seriam uma das respostas plausíveis. O termo "heterocronia" nasceu no campo da biologia e diz respeito à geração de partes do corpo em época diferente daquela que nascem normalmente, conforme a necessidade e a evolução do ser - levando a mudanças em seu tamanho e forma. Este conceito se apresenta de modo muito pertinente quando buscamos falar de reuso, requalificação, reforma, retrofit, rearquitetura de edifícios históricos, uma vez que estes precisam acompanhar a evolução da qual queremos que façam parte.

\section{ALGO DE TEORIA E SEUS PENSADORES}

Para podermos formatar uma ideia geral e consolidar uma noção de evolução de nosso pensamento, é preciso saber o que já aconteceu, o que já foi pensado e de que forma chegou a ser eventualmente realizado. O que diziam os teóricos há algum tempo atrás? $\mathrm{O}$ que dizem hoje os pensadores da arquitetura? É tão grande e eclética a resposta aos atuais dilemas envolvendo patrimônio histórico que encontramos desde o total descaso para com estas construções a projetos extremamente criativos e que respondem aos atuais anseios desta nova sociedade dinâmica, rápida e inovadora.

Já no século XIX, o filósofo escocês Thomas Carlyle expunha sua preocupação quan- 
do falava sobre a Revolução Industrial: "Não é somente o mundo físico que está agora organizado pela máquina, mas também nosso mundo interior espiritual (...) nossos modos de pensamento e nossa sensibilidade. Os homens tornaram-se tão mecânicos em seu espírito e corações quanto em suas mãos" (in CHOAY, 2006, p.20). Nas mesmas proporções de Carlyle, como fica nosso espírito, nossa sensibilidade, nossa maneira de pensar e consequentemente de viver, na atual revolução da hiperconectividade, do virtual e do sem tempo na qual estamos inseridos? Como materializar nosso tempo, nosso momento, em nossas obras, em nossa arquitetura?

De acordo com Zygmunt Bauman e seu conceito de vida líquida, as realizações individuais hoje não se solidificam em posses permanentes, não têm forma definida. A fluidez da existência contemporânea leva a um alucinante ritmo destrutivo-criativo no qual a existência é transformada em efemeridade. A liquidez é a essência máxima do ser contemporâneo. Ainda conforme este mesmo autor:

\begin{abstract}
a transformação das relações humanas e dos próprios homens em mercadoria produz um sentimento de fragilidade e incerteza que domina todas as esferas da vida afetiva e social. Para sobreviver, seria imperativo que o homem se libertasse de qualquer vínculo com o passado, adotando como visão de mundo a fugacidade e o aspecto descartável de seres e coisas (Bauman ${ }^{1} 2009$ ).
\end{abstract}

Tudo isso é bastante preocupante quando pensamos em patrimônio, legado, memória.

$\mathrm{Na}$ arquitetura, a atitude frente aos edifícios antigos tem duas maneiras bastantes distintas de se apresentar: ou esses edifícios têm sido negligenciados por terem sua história desconhecida, afinal, "só se preserva o que se ama, só se ama aquilo que se conhece", como explica Aloísio Magalhães (1997, p.190), ou eles têm sido catapultados por inúmeras possibilidades de reuso com incríveis projetos nas mais diferentes escalas e localizações.

\footnotetext{
Lugares que formam a paisagem urbana e que contêm elementos de cada fase social e econômica vivida pelos habitantes não só da cidade mas igualmente do toda região sob sua influência. A recriação da paisagem prevista ou motivada por propostas arquitetônicas e urbanísticas deve levar em consideração a evolução da sociedade e suas transformações básicas como elementos fundamentais do projeto (ZEIN, 1990 p.13).
}

Assim também Colin Rowe expõe em seu livro Collage City (1978) sobre o contextualismo e a maneira como a cidade se constrói: como um somatório de formas mais fatores psicológicos, sociais e políticos. Ada Huxtable (1997) critica as conversões do patrimônio em meros memoriais cujos espíritos tinham sido exorcizados, e nossa memória de certo modo editada. Segundo ela, o abandono tem seu próprio significado e mensagem, e um contato direto com o que "uma vez foi“ eventualmente desaparece com a restauração.

Francisco de Gracia (2001) menciona, já na introdução de seu livro Construir En Lo Construído, a possibilidade de preservarmos os centros históricos das cidades de um processo de degradação fisionômica, hoje agravado pelo grande desprestígio da noção de obra de arte aplicada à forma das cidades. Complementa dizendo que recuperar a cidade toda não é possível, mas que a recuperação dos centros históricos se justifica, pois são aceitos como uma das partes mais significativas da cidade. Se mantidos, reforçariam sua condição de lugares de fruição estético-artística. A re-arquitetura é uma das formas projetar algo novo 
em uma préexistência, considerando sempre sua relevância e sua posição dentro da configuração da cidade.

Re-arquitetura trata do papel do projeto ante os espaços da memória, (...) entendendo a construção da cidade moderna enquanto enfrentamento contemporâneo consciente de suas preexistências. Atua num espaço amplo, que vai do objeto ao espaço urbano. O projeto como mecanismo de intervenção, que pode, e deve, ser ao mesmo tempo restaurador e reabilitador do lugar contemporâneo (FROTA, 2004, p.114).

Todas essas maneiras de manipular a arquitetura preexistente reforçam um componente importante da memória: a evolução. Uma evolução que registra o "querer da arte" (Kuntswollen conceito nomeado por Aloïs Riegl ${ }^{2}$ em 1903) de cada época. O valor histórico para Riegl está diretamente relacionado com a própria noção de história.

Forma, tipologia e memória coletiva participam na construção da cidade segundo Aldo Rossi (1995). Neste sentido, o processo dinâmico da cidade tende mais à evolução do que à conservação. A função é insuficiente para definir a continuidade. Se um edifício está desocupado por um certo tempo, é sinal de que a atividade nele anteriormente executada não existe mais, ou mudou de lugar - o edifício torna-se teoricamente desnecessário. É preciso que outra atividade, de uma nova forma, seja inserida para que ele possa continuar sendo usado.

\section{NOVAS DIRETRIZES}

Levando-se em consideração o anteriormente colocado, que nossa sociedade está diferente, muito mais volátil e dinâmica, e que esta condição não tem volta, é preciso fazer com que os espaços destinados aos novos modos de vida em grandes aglomerações respondam a estas necessidades. E devemos fazê-lo de forma criativa, expressando nosso desejo artístico atual e acima de tudo combinando de maneira inteligente o que já existe com o novo que será construído. O fato de um edifício ser antigo não é um obstáculo para um novo projeto, mas sim um fundamento para seu desenvolvimento. A combinação do familiar, ou seja, da preexistência, com o novo, abre diversos modos de interpretação e de comportamento dos futuros usuários com relação à arquitetura. Transformações arquitetônicas inovadoras são possíveis e estas combinações se dão de diferentes formas e em diferentes graus. Os resultados nascem a partir da necessidade de ajustar, acrescentar, modificar e adaptar edifícios existentes às demandas contínuas da vida e às mudanças de nossas sensibilidades. Uma nova mentalidade com relação à compatibilização de novas partes com as edificações históricas, assim como do edifício histórico a ser preservado e seu entorno, são fundamentais para o processo de permanência dos imóveis inventariados. Apenas o uso justifica ou dá condições de longevidade às edificações. Marta Bogéa (2009) diz que não se trata de buscar uma materialidade fixa, mas de compreender como a materialidade estável, intrínseca à disciplina arquitetônica, pode permitir a inquietante e crescente mobilidade procurada desde o início da modernidade.

A autora Françoise Bollack (2013), em seu livro Old Buildings New Designs, expõe didaticamente formas de reutilização de edifícios antigos incorporando novas partes a estes para torná-los novamente ativos no contexto da cidade. O resultado é uma forma de heterocronia cujo objetivo é a permanência do patrimônio nas atividades cotidianas dos moradores da cidade. Buscando uma motivação extra na imaginação e na percepção perante as edifi- 
cações e suas novas partes, ela fala de estratégias como "parasitas, inserções, invólucros, justaposições e tramas".

\begin{abstract}
As novas propostas para reuso de edifícios podem e devem ser liberadas da expectativa limitante que significam a tradição no modo de atuação e as respostas padrão normalmente usadas. Usando diferentes métodos se criam novos contextos nos quais os trabalhos são criados. Eles incluem memória, mas não a memória que coleta cotações estilísticas, mas uma memória mais profunda, que inclui o modesto e o mundano, dando ao arquiteto liberdade para manufaturar novas formas, realidades fragmentadas que não são "formas" no seu significado usual, mas transformadas em entidades que reconfiguram nossa atitude frente ao tempo e ao mundo construído (BOLLACK,2013, p.11, tradução nossa).
\end{abstract}

No caso da estratégia denominada de "inserção", um novo edifício é inserido num antigo, usando a estrutura preexistente como proteção, aninhando o novo em seu interior. O objeto resultante depende das duas partes. Como coloca Bollack (2013), a parte inserida tem sua própria identidade e cria seu próprio mundo, que é enriquecido pela experiência de convívio com o antigo. A parte contentora carrega as memórias e as emoções guardadas, enquanto a nova providencia exatamente o novo, ou seja, o novo uso e uma nova relevância para a estrutura que agora é reanimada. Esta abordagem reocupa alguma estrutura normalmente marginal ou modela um novo componente dentro de um tecido histórico relevante.

Exemplos históricos podem ser buscados como a Galeria Degli Uffizi, que sofreu uma intervenção deste gênero em 1559 quando os Medici necessitaram de mais espaço do que existia no Pallazzo Vecchio. Desenhado por Giorgio Vasari, o novo edifício em forma de "U" foi inserido dentro do denso tecido da cidade criando um novo espaço público que se abre para o rio. O que caracteriza a inserção é o fato de o novo ter apenas uma fachada, a que forma a praça, enquanto as outras estão escondidas no tecido medieval, quase não diferençável deste.

Um exemplo atual é uma antiga fábrica de queijos na renomada Tribeca, em Nova York, onde um edifício foi mantido e reutilizado seguindo essa mesma estratégia. A fachada composta por três arcos em ferro fundido construída em 1871 foi mantida e restaurada. A nova inserção é um pouco menor que o antigo edifício e essa separação é como um espaço intersticial entre os dois, que permite a iluminação do espaço interno e cria um pórtico, posicionado a alguns metros da antiga fachada. Como uma máscara, a pele de metal encobre a nova parede criada em blocos de vidro que funciona como um pano de fundo neutro na frente do qual a fachada trabalhada é facilmente lida. Essa maneira de deixar o novo flutuando dentro do antigo aumenta a percepção da relação de "contém" e de "está contido" que se estabelece entre os dois prédios. Nesse gesto, a cenografia urbana é mantida, uma vez que a escala e a relação com a rua são as mesmas de quando o edifício foi construído (fig.1). 

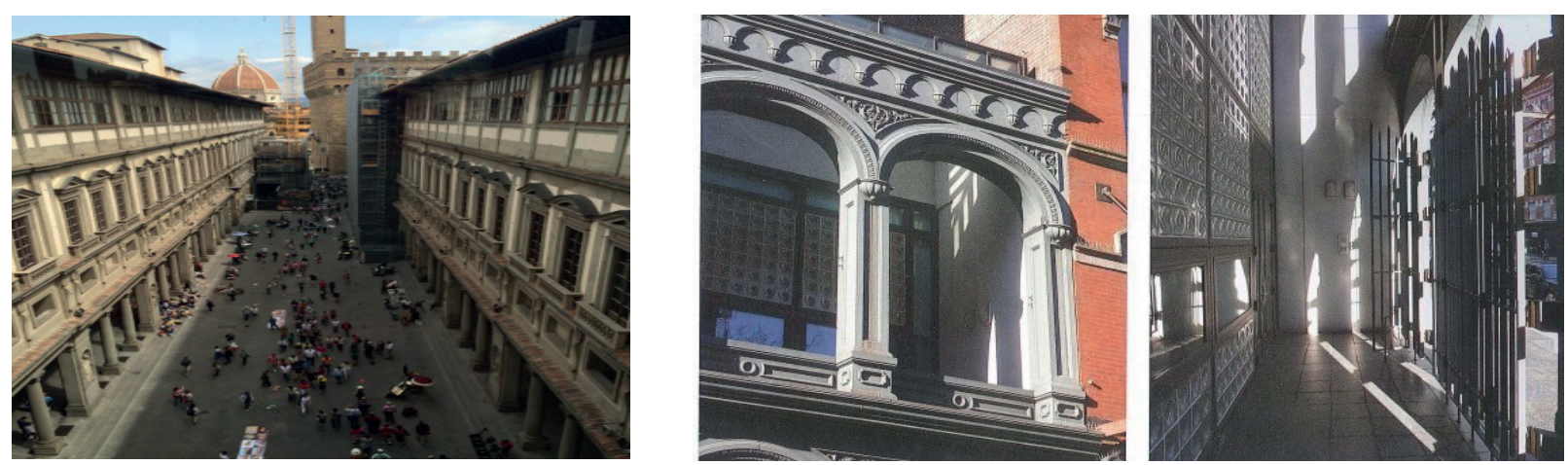

Figura 1: Vão interno da Galeria Degli Ufizzi - foto da autora e Edifício em NY - Fonte: BOLLACK 2013, p.29)

Já na opção de se trabalhar com uma edificação "parasita", as condições são um pouco diferentes. O termo "parasita" tem uma conotação negativa, uma vez que sua existência significa estar às custas do outro no qual ele se aloja. Entretanto, segundo Bollack (2013), essa relação pode ser também de simbiose, onde os dois se beneficiam. O mesmo pode ocorrer também em intervenções arquitetônicas: o edifício original abastece o conjunto das funções chave, como suporte estrutural, acessos e integração com o entorno e a adição promove novos espaços e faz um convite à releitura de uma situação para a qual certos usos não foram previstos na preexistência (fig.2). A adição não pode sobreviver sem o suporte do edifício original, e é sempre facilmente distinguida por seus materiais, cores ou forma. Volume, posição e manipulação da escala são também fatores a serem considerados. O edifício existente é que origina a forma no parasita e o modo de interação entre os dois, sendo grandes as possibilidades oferecidas para colagens e justaposições sem cortes, descreve Bollack (2013).

Historicamente esse tipo de estratégia era usada de maneira um pouco diferente de como é usada nos dias de hoje. Atualmente são exploradas as possibilidades formais e sensoriais de distinção entre os dois prédios. Exemplos mais antigos mostram a busca da composição que borra as diferenças entre novo e velho. A visão era de um edifício totalmente novo que estaria incorporando o original em sua composição. Como as composições eram baseadas em simetria, repetição, alinhamentos e hierarquias de escala e forma, a adição era mais facilmente incorporada usando essas mesmas regras.
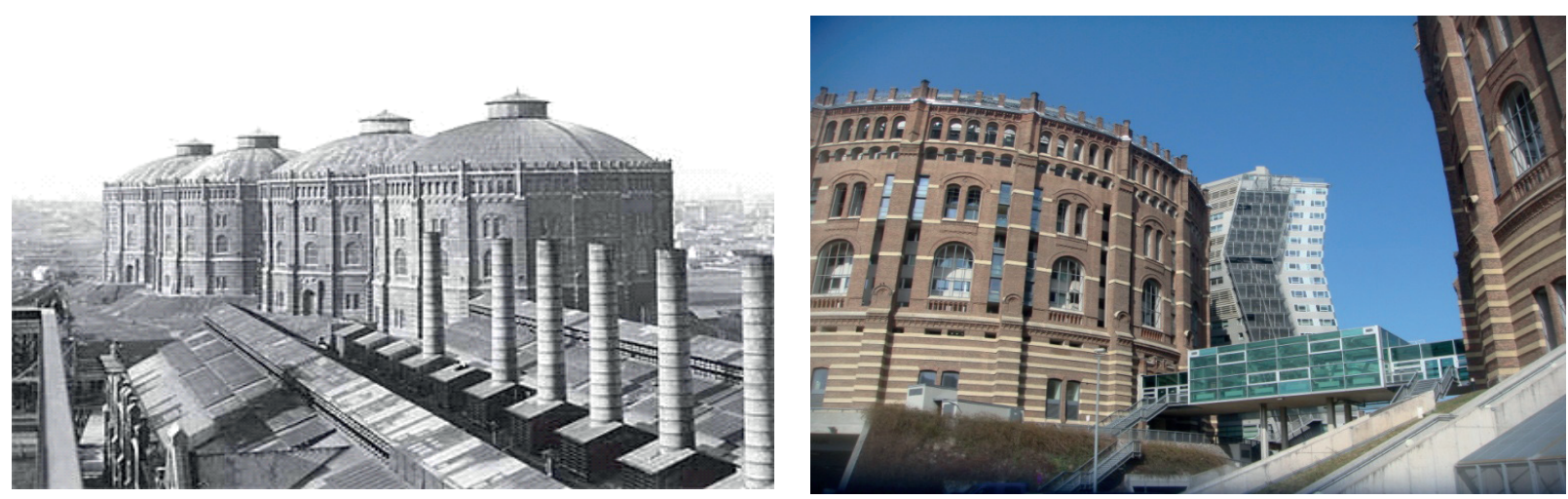

Figura 2: Edifícios originais - fonte: site Wiener Gasometer e sua reutilização com um parasita - foto da autora.

O objetivo maior é sempre buscar o diálogo entre o novo e o antigo, sabendo-se que este deve flutuar entre a autonomia e a codependência. Uma "conversa" especial entre for- 
mas e tempos, como diria Fernando Diez (2013).

Uma terceira opção de projeto seria o "invólucro". De diferentes maneiras, um novo edifício pode envolver um antigo: sobrepondo-se a ele como uma cobertura de proteção, abraçando-o em todo seu perímetro ou até mesmo encapsulando-o. Esta nova pele tem a intenção clara de proteger o existente, assim como modernizar o já familiar, considerando-o sempre distinto do preexistente. Palladio já utilizava esse conceito em 1546 quando projetou o invólucro que reconstituiria o Pallazzo de La Regione, em Vicenza, hoje conhecido como a Basílica Palladiana. Após intervenções anteriores, o Pallazzo sofreu um colapso em uma de suas esquinas, permanecendo assim por algumas décadas. Palladio interviu construindo em volta do antigo e escuro edifício um invólucro de pedra clara.

De uma maneira mais sutil e atual, o mercado Santa Caterina, em Barcelona, foi reformado segundo o princípio aqui descrito: o de envolver o antigo com o novo. Construído em 1848, foi o primeiro mercado coberto da cidade. O projeto buscou acrescentar o que fosse necessário sem desmanchar praticamente nada. Uma cobertura ondulada colorida envolve o antigo edifício e o torna perceptível já a algumas quadras de distância. Como uma manta feita de coloridos azulejos de Sevilha, a nova cobertura ondulada é suportada por três imensas vigas que passam em alguns momentos através das curvas. As entradas permanecem nas antigas portas de arco das fachadas originais. $O$ avanço da cobertura protege as paredes originais sem tocá-las. Françoise Bollack (2013) explana que o conjunto das duas (parede mais cobertura) é que torna a solução interessante e convincente, pois sua inserção no tecido denso da cidade antiga traz nova percepção ao espaço (fig.3).
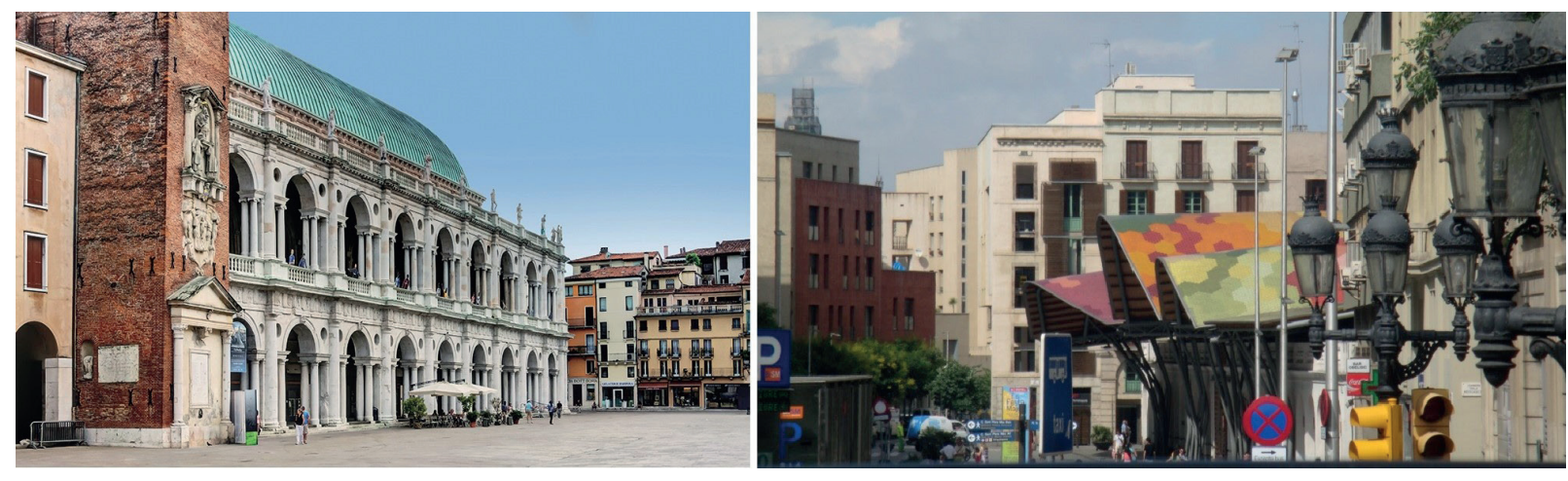

Figura 3: Basílica Palladiana - fonte: site Monumenti Nazionali. Mercado Santa Caterina, Barcelona - foto da autora.

No caso das "justaposições" ou em intervenções justapostas, a adição permanece próxima ao edifício original, sem entrar num diálogo óbvio com a estrutura antiga, diz Bollack (2013). O original permanece inteiramente legível, sem misturar fronteiras - não há o que ela intitula como "chamadas e respostas". Sua contribuição ao conjunto se dá com uma certa indiferença, uma certa distância. A separação visual se dá pelo uso de diferentes materiais, estilos, cores e texturas contrastantes ou uma abstração formal, o que incrementa o valor individual de cada parte.

A adição de Gunnar Asplund à corte de Göteborg pode ser mencionada como um exemplo de sucesso da estratégia de justaposição. Este trabalho é considerado como a demonstração de que uma adição moderna a um edifício histórico pode ser de certa forma 
empático a ele sem necessariamente imitá-lo. Pode ser considerado um "parceiro discreto". O edifício original de 1672 foi complementado em 1913. As diretrizes demonstram um meticuloso comprometimento com duas frentes: uma que iria simplesmente adicionar o novo volume com a mesma altura do existente com uma repetição modular e outra que usaria o desenho da fachada original como geradora da ordem da nova. A nova ala está próxima da original e separada dela por meio de um leve desnível que permite o delineamento claro das bordas de cada uma delas. Gunnar Asplund estabelece certas relações próprias de uma lógica formal integradora entre o edifício e a ampliação que projeta, o que pode ser considerado como um antecedente às atuais inquietudes sobre diálogo entre novo e preexistência, segundo Francisco de Gracia. Convém também lembrar que, conforme explica este autor, os próprios representantes da Prefeitura condicionaram o projeto à favor do respeito pelo edifício existente e a busca por uma chamada acomodação visual entre as duas peças arquitetônicas (fig.4).
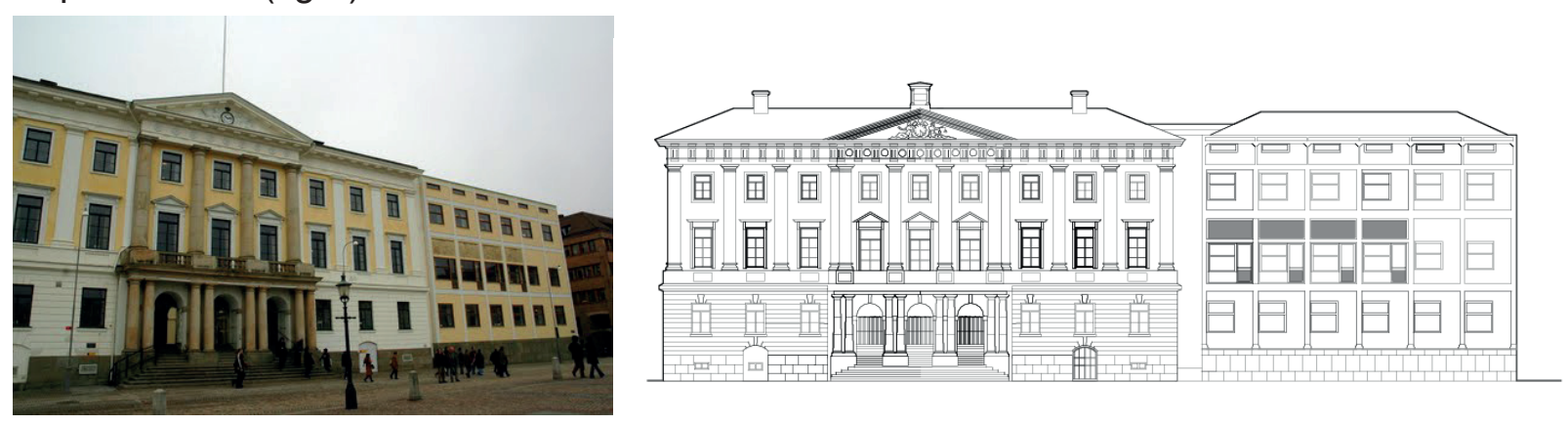

Figura 4: Prefeitura de Göteborg e sua ampliação justaposta, fonte: Bollack, 2013, p. 96.

$\mathrm{Na}$ quinta modalidade de compatibilização de novas partes a antigos edifícios a autora explica como pode funcionar um projeto baseado em uma "trama". É um trabalho complexo onde o arquiteto tece um novo desenho dentro e fora da urdidura do edifício existente. Normalmente os limites ou as costuras entre preexistente e novo não são imediatamente aparentes ou não formam um padrão reconhecível. O processo envolve o manuseio de partes existentes, deixando algumas delas intactas, trazendo outras para primeiro plano e até mesmo removendo algumas enquanto trabalha a nova edificação no tecido existente. É impossível ter uma imagem em separado no que é novo ou do que era antigo, pois eles se tornam uma coisa única.

Como exemplo, pode-se citar o Neues Museum em Berlim, onde a harmonia entre novo uso, adições e permanência é plenamente visível. Vencedor do Prêmio Mies van der Rohe no ano de 2011, o edifício foi originalmente projetado por Friedrich August Stüler e construído entre 1841 e 1859. A equipe do arquiteto David Chipperfield reconstruiu a edificação focando no restauro do volume original e respeitando a estrutura histórica. Ambas as ações (restauro e reforma do existente) são direcionadas pela ideia de que a estrutura original deveria ser enfatizada no seu contexto espacial e materialidade original - o novo deveria refletir o que foi perdido, sem imitá-lo (fig.5). 


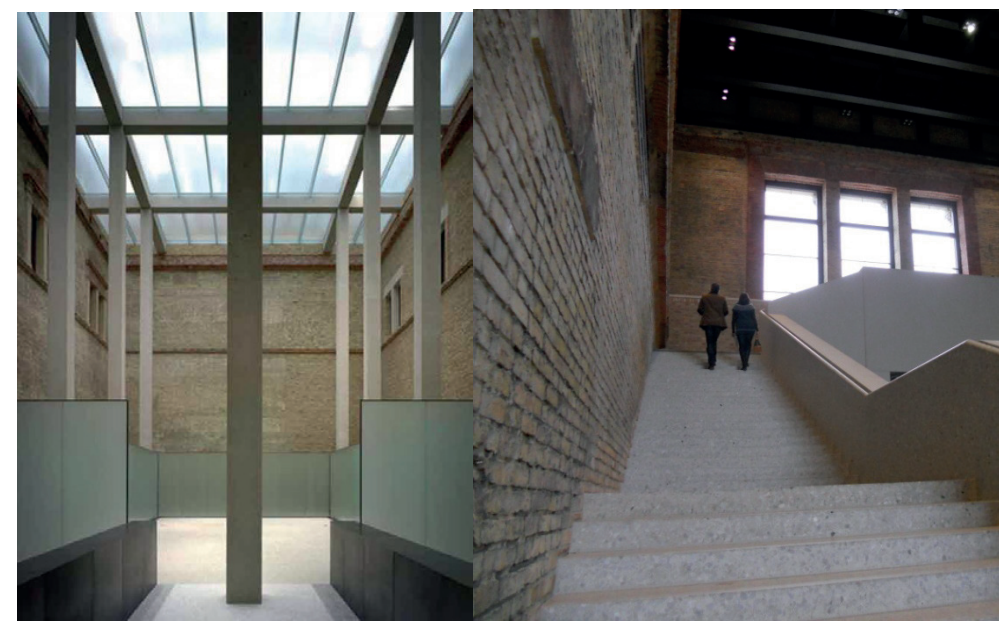

Figura 5: Interiores do Neues Museum em Berlim: novo e antigo configuram uma trama - fotos da autora.

Maneiras diversas, porém criativas, podem solucionar os impasses no tratamento do patrimônio histórico arquitetônico de uma cidade. Justamente nesta questão contribui Montaner (2001) quando diz que a "colagem" não é um mecanismo meramente visual, mas sim uma técnica ou estratégia formal contendo raízes baseadas no agrupamento de peças heterogêneas que conformam um novo objeto. Também Solá-Morales (1987) corrobora com esta concepção, afirmando que a colagem pode ser considerada como uma fotomontagem em que fragmentos autônomos produzem um significado novo e independente na arquitetura.

\section{ALGUMAS CONSIDERAÇÕES}

Quando se fala em lugar, por exemplo - esse é um conceito que, segundo Lineu Castello, em seu livro "A Percepção de Lugar: Repensando o Conceito de Lugar em Arquitetura-Urbanismo" (2007), varia conforme a experimentação de cada pessoa frente a ele e nesta mesma pessoa ao longo do tempo. "Lugar" envolve fundamentalmente a percepção obtida em novos tipos de espaços configurados para as necessidades e as práticas cotidianas de cada sociedade. Sua morfologia e sua gênese determinam os tipos de lugares. Essas características definem se esses lugares são ou não detentores da qualidade entendida como "urbanidade". Os projetos de arquitetura que viabilizam a permanência do patrimônio buscam com frequência transformá-los de meros espaços a lugares especiais. "Buscam reforçar a imagem de urbanidade que um lugar deve conter e poder transmitir às pessoas, seja de forma visual, sensorial ou informacional. O espaço transforma-se em lugar à medida que adquire definição e significado" (TUAN, 1983, p.3; 6;151 apud CASTELLO, 2006, p.60).

Ignasi Solá-Morales descreve as intervenções como uma sequência lógica para as edificações uma vez que a ideia de conservação não tem outra solução além de introduzirem-se mecanismos de vitalização para que se evite a degradação. Para ser portadora de função e significado, a edificação deve ter sua permanência viabilizada. O autor James Douglas (2011) enuncia em seu livro Building Adaptation as razões, as vantagens e as desvantagens de se adaptar edifícios antigos.

São as seguintes razões que levariam ao reuso e à adaptação: a) as garantias disponíveis: em alguns os edifícios existentes podem servir de garantia para o financiamento das obras de adaptação; b) tempo: dependendo do projeto, o tempo despedido em obra é muito menor do que de construção de um novo edifício; c) deterioração: a adaptação pode se 
fazer necessária para cessar a deterioração e um esquema de adaptação sensato estende a vida econômica de um edifício aumentando seu valor; d) desempenho: a necessidade de melhoras em termos acústicos, térmicos, estruturais e de acessibilidade é geralmente uma das razões para a adaptação; e) mudança de uso: quando um edifício fica vazio por um certo tempo, prova que sua atividade anterior não é mais demandada; em outras palavras, o edifício se torna 'desnecessário'. Um reuso adaptativo pode ser necessário para garantir a sua ocupação, que é sempre benéfica; f) restrições legais: a falta de conservação de edifícios inventariados por exemplo, ou seu abandono, pode acarretar multas para o proprietário, que o deixa dilapidar pelo tempo. A alternativa é adaptar o edifício para outro uso; g) conservação: razões culturais e técnicas são grandes influenciadoras na decisão de adaptar um edifício uma vez que suas características arquitetônicas e de importância histórica são suficientes para mantê-lo a salvo, de preferência sempre ativo; h) sustentabilidade: reuso e upgrading de edifícios são muito mais sustentáveis do que envolver a demolição e a nova construção de um edifício - muito mais energia e também resíduos serão despendidos e gerados.

Vantagens que podem ser elencadas para o reuso: a) econômicas: não são difíceis de encontrar - menor tempo despedido, superestruturas já disponíveis (ao contrário das demolições, que além de caras, são perigosas); b) técnicas: a estrutura existente pode se reutilizada, inclusive para estocar os novos materiais, além da possibilidade de uso durante a obra em alguns casos; c) espaciais: as áreas permitidas de construção são normalmente menores do que as 'cascas' existentes: subdivisões e novas repartições podem ser feitas na área construída sem comprometer as qualidades arquitetônicas dos edifícios externamente; d) ambientais: com um projeto sensível e adequado, o edifício ficará melhor do que estava antes, o que provoca uma ressonância em seu entorno. A adaptação de edifícios em áreas consolidadas diminui a pressão para novas construções em áreas ainda verdes, estimulando a otimização de infraestruturas já instaladas; e) sociais: a manutenção das características da paisagem urbana é sempre melhor atendida quando se adapta um edifício existente. Uma reafirmação psicológica do lugar é também obtida, ainda segundo Douglas (2011).

Sem dúvida a primeira ideia é sempre adaptar, reusar, renovar, manter. No entanto, nem todos os projetos de adaptação se mostram adequados ou valem a pena. É necessário bom senso para saber quando um edifício deve ser removido e abrir espaço para novas possibilidades mais adequadas e mais atraentes para o local. Douglas (2011) expõe ainda de algumas desvantagens que devem ser consideradas ao se pensar em adaptar edifícios antigos: a) funcional: não existem garantias de que o edifício será apto para receber as novas atividades - algumas restrições de layout, forma e escala já demonstraram que às vezes a adaptação é mais problemática que uma nova construção; b) técnica: a vida útil estendida de um edifício reformado ainda assim é menor do que a de um edifício novo - de fato alguns 'defeitos' que permanecem podem se tornar extremamente caros e impossíveis de serem resolvidos; c) econômica: a manutenção de um edifício antigo, mesmo que remodelado, poderá ser mais cara do que a de um novo. Assim também materiais que sejam adequados à adaptação podem ser bastante dispendiosos. Muitas vezes é necessária a construção de novas partes em diferentes tamanhos, o que pode trazer elevado custo para a operação; d) ambiental: nem todos os edifícios adaptados conseguem obter graus de conforto desejados. Às vezes, o novo uso proposto também não é adequado ao entorno existente em termos 
de densidade ou de natureza; e) legal: a adaptação total às normas e exigências colocadas atualmente para as construções podem ser difíceis de serem atendidas por edifícios antigos - esta pode ser uma grande restrição ao reuso.

Concluímos que a evolução e o desenvolvimento estão muito condicionados a alterações: o patrimônio não tem como permanecer congelado no tempo. Para certos autores, a melhor defesa de uma arquitetura histórica autêntica é o complemento de uma autêntica arquitetura contemporânea. É uma arquitetura que transforma e preserva simultaneamente. Ela transforma justamente por se reconhecer como parte do processo histórico, num diálogo de tempos e não de submissão.

É visível, entretanto, o descompasso entre as estruturas duráveis e os fluxos nas cidades atuais. As cidades são metabolismos e estão em permanente alteração, consequência das mudanças econômicas, sociais e também de produção imobiliária - uma vez que a distribuição do uso não é aleatória. Toda intervenção é uma tentativa de que o edifício volte a se manifestar nas atividades cotidianas das cidades. Métodos mais sutis de alcançar ligações harmônicas entre o antigo e o novo devem existir principalmente onde se pretende que o tecido existente venha a ser ressuscitado e transformado por estas intervenções. $O$ patrimônio histórico precisa estar presente no planejamento das cidades, como uma de suas características mais influentes. É fundamental pensar de maneira global para que a decisão local seja correta, isto é, com uma visão de urbanismo, que inclua as áreas de interesse cultural como ponto atrativo e que valorize os espaços livres como áreas de conexão. O papel do espaço público na revitalização urbana e no reuso de preexistências se reforça ainda mais quando pensado e projetado como catalisador da vivência e da urbanidade em nossas cidades, uma vez que traz massa crítica para que isto aconteça.

"A boa arquitetura de um determinado período vai sempre bem com a de qualquer período anterior, o que não combina com coisa alguma é a falta de arquitetura" (COSTA, apud MOTTA, 1987, p. 110).

\section{NOTAS}

1. Zygmunt Bauman (1925-2017): foi um sociólogo polonês, professor emérito das Universidades de Leeds e Varsóvia. Sua teoria da vida líquida fala sobre a ansiedade e a angústia que é viver em nossa atual condição sociocultural, marcada por infinitas possibilidades de escolhas e pela falta de solidez e durabilidade em todas as esferas da vida humana: relações afetivas, trabalho, conhecimento.

2. Aloïs Riegl foi um historiador de arte vienense, nomeado em 1902 presidente da comissão de Monumentos Históricos da Áustria e por ela encarregado de empreender a reorganização da legislação de conservação de monumentos austríacos.

\section{REFERÊNCIAS}

BAUMAN, Zigmunt. Vida líquida. Rio de Janeiro: Zahar, 2009.

BOGÉA, Marta. Cidade Errante: Arquitetura em Movimento. São Paulo: Editora SENAC, 2009. 
BLOZSIES, Charles. Old Buildings, New Designs. New York: Princeton Architectural Press, 2012.

BOLLACK, Françoise Astorg. Old Buildings New Forms: New Directions in Architectural Transformations. New York: The Monacelli Press, 2013.

CASTELLO, Lineu. A percepção de lugar: repensando o conceito de lugar em arquitetura urbanismo. Porto Alegre: PROPAR/UFRGS, 2007.

CHOAY, Françoise. A alegoria do patrimônio. São Paulo: Editora Estação Liberdade: UNESP, 2006.

DIEZ, Fernando. Reutilizando o passado recente. Revista Summa+, Buenos Aires, n. 128, p. 4-5, 2013.

DOUGLAS, James. Building Adaptation. London: Spon Press, 2011.

FROTA, ArthurD'Aló. Re-arquiteturas. Arqtexto, Porto Alegre, n. 5, p. 110-141, 2004. Disponível em: <http://www.ufrgs.br/propar/publicacoes/ARQtextos/PDFs revista 5/10 Jos\%C3\%A9\%20Artur\%20 D\%E2\%80\%99Al\%C3\%B3\%20Frota.pdf>. Acesso em: 24 jun.2014.

GRACIA, Francisco de. Construir en Lo Construido: laarquitectura como modificación. 3. ed. rev. Madrid: Nerea, 2001.

GRASSI, Giorgio. Architecture, Dead Language. Milano: Electa, 1988

HUXTABLE, Ada Louise. The Unreal America: Architecture and Illusion. New York: The New Press, 1999.

MAGALHÃES, Aloísio. A questão dos bens culturais no Brasil. Rio de Janeiro: Nova Fronteira, 1997.

MONTANER, Josep Maria. Depois do movimento moderno: arquitetura da segunda metade do século XX. Barcelona: Editorial Gustavo Gili, 2001.

MOTTA, Lia. O SPHAN em Ouro Preto: uma história de conceitos e critérios. Revista do Patrimônio Histórico e Artístico Nacional, Brasília, n. 22, p. 108-122, 1987. Disponível em: <http://portal.iphan.gov.br/ publicacoes/lista?categoria=\&busca=O+SPHAN+em+outro+preto>. Acesso em: 24.jun.2014.

MUÑOZ, Francesc. Urbanalización: paisajes comunes, lugares globales. Barcelona: Editorial Gustavo Gili, 2008.

RIEGL, Aloïs. O Culto Moderno aos Monumentos: a sua essência e a sua origem. São Paulo: Perspectiva, 2016. (orig. 1903).

ROSSI, Aldo. A arquitetura da cidade. São Paulo: Martins Fontes, 1995.

SANTOS, Carlos Nelson F. A cidade como um jogo de cartas. São Paulo: Projeto Editora,1988.

ZEIN, Ruth Verde. Há de se ir às obras. Revista Summa+, Buenos Aires, n. 128, p. 120-121, 2013.

Recebido em: 06/09/2018

Aceito em: 21/09/2018 